\title{
Preoperative downstaging chemoradiation with concurrent irinotecan and capecitabine in MRI-defined locally advanced rectal cancer: a phase I trial (NWCOG-2)
}

\author{
SW Gollins*,I, S Myint ${ }^{2}$, S Susnerwala ${ }^{3}$, B Haylock², M Wise ${ }^{3}$, C Topham ${ }^{4}$, L Samuel ${ }^{5}$, R Swindell ${ }^{6}$, J Morris ${ }^{1}$, \\ L Mason ${ }^{6}$ and E Levine ${ }^{\text {w,7 }}$
}

'Department of Clinical Oncology, North Wales Cancer Treatment Centre, Rhyl LLI 8 5UJ, UK; ' Department of Clinical Oncology, Clatterbridge Hospital, Liverpool CH63 4JY, UK; ${ }^{3}$ Department of Clinical Oncology, Royal Preston Hospital, Preston PR2 9HT, UK; ${ }^{4}$ Department of Clinical Oncology, St Lukes Cancer Centre, Guildford GU2 7XX, UK; ${ }^{5}$ Department of Clinical Oncology, Aberdeen Royal Infirmary, Aberdeen AB25 2ZB, UK; ${ }^{6}$ Department of Medical Statistics, The Christie Hospital NHS Trust, Manchester M2O 4BX, UK; ${ }^{7}$ Department of Clinical Oncology, The Christie Hospital NHS Trust, Manchester M20 4BX, UK

BACKGROUND: The aim of this study was to investigate the safety of neoadjuvant chemoradiation using radiotherapy (RT) combined with concurrent capecitabine and irinotecan for locally advanced rectal cancer before surgery.

METHODS: Forty-six patients were recruited and treated on the basis that MRI scanning had shown poor-risk tumours with threatening $(\leqslant 1 \mathrm{~mm})$ or involvement of the mesorectal fascia. Conformal RT was given using 3 or 4 fields at daily fractions of I.8 Gy on 5 days per week to a total dose of $45 \mathrm{~Gy}$. Concurrently oral capecitabine was given twice daily throughout radiotherapy continuously from days I to 35 and intravenous irinotecan was given once per week during weeks I to 4 of RT. Dose levels were gradually escalated as follows. Dose level I: capecitabine $650 \mathrm{mg} \mathrm{m}^{-2}$ b.i.d. and irinotecan $50 \mathrm{mg} \mathrm{m}^{-2}$; Dose level 2: capecitabine $650 \mathrm{mg} \mathrm{m}^{-2}$ b.i.d. and irinotecan $60 \mathrm{mg} \mathrm{m}^{-2}$; Dose level 3: capecitabine $825 \mathrm{mg} \mathrm{m}^{-2}$ b.i.d. and irinotecan $60 \mathrm{mg} \mathrm{m}^{2}$; Dose level 4: capecitabine $825 \mathrm{mg} \mathrm{m}^{-2}$ b.i.d. and irinotecan $70 \mathrm{mg} \mathrm{m}^{-2}$.

RESULTS: Diarrhoea (grade 3, no grade 4) was the main serious acute toxicity with lesser degrees of fatigue, neutropenia, anorexia and palmar-plantar erythrodysesthesia. The recommended dose for future study was dose level 2 at which 3 of 14 patients (2l\%) developed grade 3 diarrhoea. Postoperative complications included seven pelvic or wound infections and two anastomotic and two perineal wound dehiscences. There were no deaths in the first 30 days postoperatively. Of 4 I resected specimens, II (27\%) showed a pathological complete response ( $\mathrm{PCR}$ ) and five (I2\%) showed an involved circumferential resection margin (defined as $\leqslant 1 \mathrm{~mm})$. The 3-year disease-free survival (intent-to-treat) was 53.2\%.

CONCLUSION: In patients with poor-risk MRI-defined locally advanced rectal cancer threatening or involving the mesorectal fascia, preoperative chemoradiation based on RT at $45 \mathrm{~Gy}$ in 25 daily fractions over 5 weeks with continuous daily oral capecitabine at $650 \mathrm{mg} \mathrm{m}^{-2}$ b.i.d. days I-35 and weekly IV irinotecan at $60 \mathrm{mg} \mathrm{m}^{-2}$ weeks I-4, provides acceptable acute toxicity and postoperative morbidity with encouraging response and curative resection rates.

British Journal of Cancer (2009) I 01, 924-934. doi:10.1038/sj.bjc.6605258 www.bjcancer.com

Published online 18 August 2009

(c) 2009 Cancer Research UK

Keywords: rectal cancer; MRI staging; neoadjuvant chemoradiation; capecitabine; irinotecan

The mainstay of curative treatment for rectal cancer is surgery and the surgical technique of total mesorectal excision (TME), wherein meticulous sharp dissection is carried out in the plane of the mesorectal fascia, has been shown to reduce the chance of local recurrence (MacFarlane et al, 1993; Kapiteijn et al, 2001). Perioperative RT can reduce the chance of local recurrence following rectal cancer surgery (Colorectal Collaborative Group,

*Correspondence: Dr SW Gollins;

E-mail: simon.gollins@cd-tr.wales.nhs.uk

* This manuscript is dedicated to our esteemed friend and colleague Dr Ed Levine who died on 3 March 2009

Received 22 January 2009; revised 22 July 2009; accepted 23 July 2009; published online 18 August 2009
2001). The FFCD 9203 and EORTC 22921 trials have shown that for operable rectal cancer combined fluoropyrimidine chemotherapy and long-course RT confers an advantage in terms of reducing local pelvic recurrence compared with RT alone (Bosset et al, 2006; Gerard et al, 2006). A large randomised trial has definitively shown that preoperative chemoradiation (CRT) reduces local recurrence in operable rectal cancer compared with postoperative CRT (13 vs 6\%), with reduced acute and late toxicity (Sauer et al, 2004).

Involvement of the circumferential resection margin (CRM) has been shown to be an important, independent prognostic factor, resulting in high rates of local recurrence (Quirke et al, 1986; Wibe et al, 2002), distant metastases (Hall et al, 1998; Mawdsley et al, 2005) and worse survival (Birbeck et al, 2002; Nagtegaal and Quirke, 2008), even after TME surgery (Marijnen et al, 2003). 
Several potential mechanisms have been described in which the histological CRM may be positive including direct or discontinuous tumour spread, lymph node spread, lymphovascular spread and perineural spread (Nagtegaal and Quirke, 2008). CRM positivity is also strongly related to the quality of surgery (Nagtegaal et al, 2002; Quirke et al, 2009).

In the United Kingdom and increasingly elsewhere, preoperative MRI scanning of the pelvis is viewed as the gold standard for judging threatening or involvement of the mesorectal fascial potential surgical TME resection plane. In 311 patients with operable rectal cancer who were shortly due to undergo surgery, the MERCURY trial showed that preoperative MRI has high accuracy, negative predictive value and specificity in the identification of a potentially involved CRM (MERCURY Study Group, 2006).

Approximately $20-30 \%$ of rectal cancer patients present with disease which threatens or involves the potential mesorectal surgical excision margin. These patients might be considered to have 'locally advanced inoperable' disease with a high risk of local recurrence unless some form of downstaging is carried out before surgery. As an indication of what might be achieved in the modern era using downstaging CRT with a single agent fluoropyrimidine as a radiation sensitiser in patients with locally advanced carcinomas, a single UK cancer network audit has been reported in 150 patients with locally advanced rectal cancer (Mawdsley et al, 2005). Sixtyone percent were T4 and approximately one-third had been staged by MRI. Concurrent bolus 5-FU was administered in weeks 1 and 5 of radiotherapy as per the EORTC 22921 and FFCD 9203 trials. On an intention to treat (ITT) analysis, an R0 resection was achieved in only $65 \%$ of patients and the poor prognostic significance of involved CRM post-downstaging CRT was confirmed with 3-year local recurrence at $10 v s 62 \%$ and 3-year disease-free survival at 52 vs $9 \%$ for $\mathrm{R} 0$ vs $\mathrm{R} 1 / 2$ resections, respectively.

There is a need to improve on the potency of currently available downstaging CRT regimes and one potential way of achieving this is by adding in a second chemotherapy agent to form a doublet in addition to a fluoropyrimidine. The topoisomerase-I inhibitor irinotecan is one possible agent to use in this context in view of radiosensitising properties demonstrated in vitro (Chen et al, 1997). Several early phase studies have been reported (Mehta et al, 2003; Klautke et al, 2005; Mohiuddin et al, 2006; Navarro et al, 2006; Glynne-Jones et al, 2007) including by our own group (Iles et al, 2008) concerning rectal cancer CRT regimes using the doublet of 5FU plus irinotecan as radiation sensitisers. Rates of grade 3 or 4 toxicity have varied from between $12-37 \%$ (mostly diarrhoea) with promising pathological complete response (pCR) rates of between $14-37 \%$ for resected specimens.

There are potential advantages in using the oral 5FU prodrug capecitabine rather than 5FU itself including the avoidance of a central venous catheter to administer continuous infusional 5FU. In addition, the final enzymatic conversion of capecitabine is mediated via thymidine phosphorylase which often occurs in a higher concentration in cancer tissue compared with adjacent normal tissue with the potential advantage of improving the therapeutic ratio compared with 5FU (Glynne-Jones et al, 2006). Thymidine phosphorylase is upregulated by RT (Sawada et al, 1999).

This study represents a progression of previous research reported by our group (the North West/North Wales Clinical Oncology Group) which used irinotecan and infusional 5FU as a doublet of concurrent radiation sensitisers in the preoperative downstaging of locally advanced rectal cancer (Iles et al, 2008). This study is a phase I trial in patients with MRI-defined locally advanced rectal cancer which is threatening or involving the mesorectal fascia and replaces the infusional 5FU with continuous oral capecitabine. The doses of irinotecan and capecitabine were gradually increased, keeping the radiation dose constant, with toxicity being the primary end point.

\section{PATIENTS AND METHODS}

\section{Inclusion criteria}

Male or female patients aged $\geqslant 18$ years old, of WHO performance status 0,1 or 2 were included. All had provided written informed consent to participate in the trial. Patients had histologically confirmed previously untreated carcinoma of the rectum with the distal extent within $12 \mathrm{~cm}$ of the anal verge using a rigid sigmoidoscope. They were deemed to be a candidate for preoperative downstaging chemoradiation due to T3 disease on MRI scanning $\leqslant 1 \mathrm{~mm}$ from the edge of the mesorectum or T4 disease on MRI scanning or any T3/T4 disease on MRI scanning with the distal extent of tumour $\leqslant 5 \mathrm{~cm}$ from the anal margin. Any nodal status (N0-2) was permitted and computerised tomography (CT) scanning of abdomen and pelvis had failed to detect evidence of metastatic (M1) disease. All radiological investigations were to be carried out within 4 weeks of trial registration. Patients had adequate haematology with a neutrophil count $>1.5 \times 10^{9} 1^{-1}$, platelet count $>100 \times 10^{9} \mathrm{l}^{-1}, \mathrm{Hb}>9 \mathrm{~g} \mathrm{dl}^{-1}$ (the use of blood transfusions was allowed to increase the level of haemoglobin). Patients also had adequate renal and hepatic function with serum creatinine $\leqslant 1.5 \times$ ULN, serum bilirubin $\leqslant 1.25 \times$ ULN, serum ALT, AST and alkaline phosphatase $\leqslant 2.5 \times$ ULN.

\section{Exclusion criteria}

Any of the following was regarded as a criterion for exclusion from the trial: previous systemic chemotherapy; previous radiotherapy to the planned exposure area; any severe concurrent medical condition which would make it undesirable, in the supervising clinician's opinion, for the patient to participate in the trial or which would jeopardise compliance with the trial protocol; a calculated creatinine clearance of less than $50 \mathrm{ml} \mathrm{min}^{-1}$; loss of continuity of the upper GI tract or malabsorption; a history of myocardial infarction within previous year and/or with unstable angina, arrythmia or cardiac failure; pregnancy or lactation; patients of child-bearing potential not implementing adequate contraception; previous or current malignancies at other sites, with the exception of adequately treated in situ carcinoma of the cervix uteri and basal or squamous cell carcinoma of the skin; subjects considered by the investigator to be at risk of transmitting any infection through blood or other body fluid including acquired immune deficiency syndrome, or other sexually transmitted disease or hepatitis; participation in other clinical trials; partial or complete bowel obstruction (though patients in whom this had been relieved with a defunctioning stoma, were permitted to enter the trial).

\section{Study structure}

The primary objective of the study was to determine the maximumtolerated dose (MTD) of intravenous irinotecan and capecitabine when given concurrently with long-course preoperative pelvic radiotherapy in patients who have locally advanced rectal cancer. The regime defined using the MTD of capecitabine and irinotecan could then be taken forward into a future phase II trial.

Patients were treated with a 5-week course of downstaging CRT. The dose of radiotherapy was fixed at $45 \mathrm{~Gy}$ and the aim was to gradually increase the doses of capecitabine and irinotecan in cohorts of three patients until the MTD had been defined. An MRI scan was carried out 6 weeks following CRT and surgery attempted 2 weeks following the MRI scan, that is, 8 weeks following completion of CRT. Acute toxicity was assessed weekly throughout the 5-week course of CRT then weekly for 4 weeks afterwards. Postoperative morbidity was assessed up to 30 days post surgery. Late toxicity was assessed at $6,12,24$ and 36 months post completion of CRT. 


\section{Radiotherapy}

RT was planned with patients in the prone position with a full bladder (depending on patient tolerance) and an anal marker. Either CT or fluoroscopic simulation (with rectal barium contrast) were acceptable for planning RT. Opacification of the small bowel was recommended (e.g., $300 \mathrm{ml}$ Baritop plus $20 \mathrm{ml}$ Gastrograffin orally 45-60 min before simulation). A belly board was not routinely used.

A Gross Tumour Volume (GTV) was defined using clinical evidence and pelvic radiological imaging. The Planned Target Volume (PTV) was defined as follows. Superiorly $3 \mathrm{~cm}$ superior to the most superior extent of the GTV, but PTV to extend no higher than the sacral promontory. Inferiorly $3 \mathrm{~cm}$ inferior to the most inferior extent of GTV. Posteriorly the border of the most posterior aspect of sacrum. Anteriorly $2 \mathrm{~cm}$ anterior to tumour or the anterior rectal wall whichever is the more anterior. Laterally $3 \mathrm{~cm}$ lateral to the most lateral extent of GTV.

RT was prescribed to the central axis of the beams. In the central axis section, the dose within the target area was stipulated to be no less than $95 \%$ and no more than $105 \%$ of the prescribed dose. Treatment was to $45 \mathrm{~Gy}$ in 25 daily fractions over 5 weeks, treating for 5 days (Monday-Friday) per week at 1.8 Gy per day. Three or four treatment fields were allowed and all fields were to be treated daily.

\section{Chemotherapy}

The haematologic and serum biochemical parameters outlined in 'Inclusion Criteria' (above) had to be confirmed within the week before commencing study treatment.

Capecitabine was taken continuously throughout the 5-week course of radiotherapy including weekends. The capecitabine tablets were taken twice daily approximately $12 \mathrm{~h}$ apart within $30 \mathrm{~min}$ of the ingestion of food (ideally after breakfast and evening meal) with approximately $200 \mathrm{ml}$ of water (not fruit juices), and before radiotherapy on day 1 . Irinotecan was given as a $60 \mathrm{~min}$ intravenous infusion in $250 \mathrm{ml}$ of normal saline once per week during weeks $1,2,3$ and 4 of radiotherapy (with equal, weekly spacing between infusions). There was flexibility as to which day in the week was chosen to administer irinotecan.

The starting dose (dose level 1) of capecitabine was $650 \mathrm{mg} \mathrm{m}^{-2}$ b.i.d. and irinotecan $50 \mathrm{mg} \mathrm{m}^{-2}$. The doses were then gradually escalated as follows: dose level 2: capecitabine $650 \mathrm{mg} \mathrm{m}^{-2}$ b.i.d. and irinotecan $60 \mathrm{mg} / \mathrm{m}^{2}$; dose level 3: capecitabine $825 \mathrm{mg} / \mathrm{m}^{2}$ b.i.d. and irinotecan $60 \mathrm{mg} / \mathrm{m}^{2}$; dose level 4: capecitabine $825 \mathrm{mg} /$ $\mathrm{m}^{2}$ b.i.d. and irinotecan $70 \mathrm{mg} / \mathrm{m}^{2}$.

It was planned that there would be three patients per cohort. Toxicity was assessed until 4 weeks post completion of radiotherapy that is, 9 weeks in total. If no dose-limiting toxicity (DLT) was encountered, further patients would be entered at the next higher dose level. The next dose level was not available to recruitment until toxicity data was available for the whole 9-week period for all patients on a particular dose level. If one patient developed grade 3/ 4 toxicity, then a further three patients would be added to that cohort. If there were no further episodes of grade 3/4 toxicity (i.e., one of six patients showed a DLT), then further patients would be entered at the next higher dose level. If at least two out of six patients at the same dose level developed DLT, then this was to be considered as too toxic and the next three patients were treated at the dose level lower. The highest dose level at which zero of three or one of six patients developed DLT was considered the MTD. It was the intention to use the CRT regimen at the MTD in a subsequent phase II trial in an expanded number of patients (100).

\section{Acute toxicity assessment and dose adjustment}

Toxicity was scored according to the National Cancer Institute Common Toxicity Criteria version 2.0 (published 30 April 1999).
DLT was defined as: grade 3 or 4 diarrhoea; grade 3 or 4 fatigue; grade 3 or 4 neutropenia accompanied by fever $\left(>38^{\circ} \mathrm{C}\right)$ or $\geqslant$ grade 3 infection; grade 4 thrombocytopenia; grade 4 nausea/ vomiting despite full antiemetic treatment; grade 3 palmarplantar erythrodysesthesia (Hand Foot Syndrome); dose delay of $>2$ weeks because of drug-related toxicity.

If grade 1 haematological toxicity was encountered no adjustment of RT or chemotherapy took place. For grade 2 haematological toxicity no adjustment of radiotherapy took place but chemotherapy was interrupted until grade $0-1$ then continued at $100 \%$ dose. For grade 3 haematological toxicity RT was interrupted until grade $0-1$ then continued and chemotherapy interrupted until grade $0-1$ then continued at $75 \%$ dose. For grade 4 haematological toxicity RT was interrupted until grade $0-1$ then continued and chemotherapy discontinued permanently.

If grade 1 non-haematological toxicity was encountered no adjustment of RT or chemotherapy took place. For grade 2 non-haematological toxicity daily review of RT took place but chemotherapy was interrupted until grade 0 then continued at $100 \%$ dose. For grade 3 non-haematological toxicity daily review of RT took place and chemotherapy interrupted until grade 0 then continued at $75 \%$ dose. For grade 4 non-haematological toxicity RT was discontinued unless toxicity settled to grade $0-1$ within 2 weeks when it could be continued and chemotherapy was discontinued permanently.

\section{Surgery and histopathological examination of the resected specimen}

A defunctioning stoma was permitted before CRT if judged clinically necessary because of intolerable pelvic symptoms. Total mesorectal excision was used for surgical resection. Histopathological examination of surgically resected specimens (including India inking of the CRM) was carried out according to minimum data set guidelines issued by the UK Royal College of Pathologists (Quirke and Williams, 1998).

\section{Study conduct}

The study had full UK Multicentre Research Ethics Committee approval (MREC/04/4/015), Clinical Trials Authorisation from the Medicines and Healthcare Regulatory Agency for the use of irinotecan (MF 8000/12694) and capecitabine (MF 8000/12695) and was overseen by an Independent Data Safety Monitoring Committee. It was conducted according to European Clinical Trials Directive 2001/20/EC and sponsored by Conwy and Denbighshire NHS Trust. It was included on the UK National Cancer Research Network portfolio (NCRN Trial ID: 1387). The trial was conducted in accordance with The Declaration of Helsinki and Good Clinical Practice Guidelines.

\section{Statistics}

Kaplan-Meier censored survival curves were used, plotted with regard to the 46 patients in the intent-to-treat population. Diseasefree survival was defined as the first event of local pelvic recurrence, distant metastases or death.

\section{RESULTS}

\section{Patient characteristics}

Between September 2003 and June 2005 a total of 47 patients consented to participation in the trial of which 46 commenced treatment (one patient withdrew consent before starting treatment). Details of patients and tumour characteristics are shown in Table 1. Five patients had a defunctioning stoma before treatment. 
Table I Baseline patient and tumour characteristics

\begin{tabular}{|c|c|}
\hline Gender & Number (\%) \\
\hline $\begin{array}{l}\text { Male } \\
\text { Female }\end{array}$ & $\begin{array}{l}33(72) \\
13(28)\end{array}$ \\
\hline WHO PS & $\begin{array}{l}\text { Number of } \\
\text { patients (\%) }\end{array}$ \\
\hline $\begin{array}{l}0 \\
1 \\
2\end{array}$ & $\begin{array}{c}37(80) \\
8(17) \\
1(2)\end{array}$ \\
\hline \multicolumn{2}{|l|}{ Age: median 61.5 years (range, $34-78$ years) } \\
\hline \multicolumn{2}{|c|}{$\begin{array}{l}\text { Distance from distal tumour margin to anal verge using rigid sigmoidoscope: } \\
\text { Median } 7.0 \mathrm{~cm} \text { (range, } 0-12.0 \mathrm{~cm})\end{array}$} \\
\hline Location & $\begin{array}{l}\text { Number of } \\
\text { patients (\%) }\end{array}$ \\
\hline $\begin{array}{l}0-5 \mathrm{~cm} \\
>5-10 \mathrm{~cm} \\
>10-12 \mathrm{~cm}\end{array}$ & $\begin{array}{c}12(26) \\
30(65) \\
4(9)\end{array}$ \\
\hline Local stage (MRI) & $\begin{array}{l}\text { Number of } \\
\text { patients (\%) }\end{array}$ \\
\hline T3 & $38(83)$ \\
\hline T4 & $8(17)$ \\
\hline No & $10(22)$ \\
\hline NI & $26(56)$ \\
\hline N2 & $10(22)$ \\
\hline \multicolumn{2}{|l|}{ Relation of primary tumour to mesorectum (MRI) } \\
\hline Mesorectal fascia not involved ${ }^{\mathrm{a}}$ & 4 \\
\hline $\begin{array}{l}\text { Mesorectal fascia potentially involved ( } \leqslant 1 \mathrm{~mm} \text { from } \\
\text { primary tumour) }(n)\end{array}$ & 15 \\
\hline $\begin{array}{l}\text { Mesorectal fascia involved but not breached by primary } \\
\text { tumour) ( } n \text { ) }\end{array}$ & 12 \\
\hline Mesorectal fascia breached $(n)$ & 15 \\
\hline
\end{tabular}

a Low third cancers $\leqslant 50 \mathrm{~mm}$ from anal verge, one with definite involvement of external anal sphincter.

\section{Treatment-related toxicity/dose intensity}

Details of toxicity at the various dose levels are illustrated in Table 2. The most common grade 3 toxicity was diarrhoea (recorded overall in 10 patients), Other grade 3 toxicities (some overlapping), which occurred included fatigue (three patients), anorexia (two patients), uncomplicated neutropenia (three patients), neutropenic fever (two patients), nausea/vomiting (two patients), palmar-plantar erythrodysesthesia (PPE) (one patient), abnormal liver enzymes (one patient) and hypertension (one patient).

At dose level 1 there were no dose-limiting toxicities and thus the trial progressed to dose level 2.

One of the first three patients on dose level 2 developed a protocol-stipulated DLT (grade 3 diarrhoea) and thus three additional patients were added on this dose level with no further DLTs. Progression was then made to dose level 3.

Owing to an administrative error, seven patients were initially treated at dose level 3 . One of these suffered a DLT (grade 3 fatigue). One other patient, a 72-year-old female, who had been well, presented with an acute neurological event on day 22 of therapy, characterised by almost complete dysphagia, marked drowsiness and nausea suggesting a possible brain stem cerebrovascular accident although this was not confirmed on an MRI scan. No further chemotherapy was given although she went on to complete her RT after an 8-day delay with a subsequent slow neurological recovery over the following 2 months. There was uncertainty as to the nature of this episode, particularly in view of the fact that she did not show other anticipated treatment-related toxicities (no diarrhoea, neutropenia or dehydration) and in view of this progression was then made to dose level 4 .

On dose level 4, two of six patients experienced DLT (grade 3 diarrhoea and neutropenic fever) and thus the trial stepped down a dose level back to dose level 3 as the provisional initial recommended dose for expanding out for treatment of an increased number of patients.

Of the first additional 16 patients treated at dose level 3 however, seven developed a DLT. This meant that a total of 8 of 23 patients (34\%) treated on dose level 3 had developed at least one DLT (Table 3).

After review of the data by the Independent Data Safety Monitoring Committee, dose level 2 was chosen as the revised recommended dose at which to include further patients. A further eight patients were then treated at dose level 2 of which two developed a DLT (grade 3 diarrhoea). Thus in total, 3 of 14 patients (21\%) at dose level 2 developed a DLT, which was considered acceptable as a recommended dose to use in future studies.

The consort flowchart showing the flow of patients through the study is shown in Figure 1. Of the 46 patients who commenced treatment, five (11\%) did not undergo surgical resection and their details are as follows.

A 68-year-old female patient (dose level 3) had been well until week 4 of treatment, being admitted as an emergency on day 28 of her treatment course. She experienced a rapid onset of diarrhoea and on admission was dehydrated with grade $3 \mathrm{PPE}$, grade 3 neutropenia, marked mucositis and hypoalbuminaemia. She was treated with full supportive measures including intravenous rehydration and broad spectrum antibiotics but her condition continued to deteriorate, resulting in her death from pneumonia a week post admission. A 59-year-old male patient (dose level 3) developed liver metastases on re-staging. A 73-year-old male patient (dose level 3) completed CRT but was found to have unresectable disease on re-staging. A 65-year-old male patient (dose level 2) completed CRT but suffered a gradual deterioration in general condition, which meant that he was never fit for resection, dying approximately a year later. Finally, a 66-year-old female patient developed a recto-vaginal fistula during CRT, completing only 19 fractions of radiotherapy. She experienced a rapid deterioration in her general condition resulting in death.

One male patient (dose level 3) developed intraoperative bleeding and had a cardiac arrest and died on the operating table, immediately following resection of his cancer.

Overall 5 of 13 females (38\%) developed a grade- 3 toxicity compared with 8 of 33 males (24\%) although this difference was not significant using $\chi^{2}(P=0.55)$.

Dose intensity that was achieved, expressed in terms of the average percentage of the total intended dose that could be delivered at each dose level is shown in Table 4. At all dose levels at least $96 \%$ of the intended dose of RT was able to be delivered and at least $93 \%$ of the intended dose of irinotecan. However, the achievable dose intensity of capecitabine was lower with only $82 \%$ deliverable at dose levels 3 and 4 . At the eventual recommended dose level 2, the achievable dose intensities were: RT $100 \%$, irinotecan $96 \%$ and capecitabine $91 \%$.

\section{MRI post chemoradiation}

Forty-three patients had a second MRI post CRT. Three patients did not have a second MRI because of death during CRT of one patient, development of a recto-vaginal fistula during CRT in one patient with rapid clinical deterioration then death and patient refusal in a third (subsequently resected with a negative CRM).

Comparing pre- $v s$ post-CRT MRI scans (Table 5), 18 patients (42\%) were judged to have had their T-stage downstaged, 25 (58\%) unchanged and none upstaged. None of nine patients with N0 
Table 2 Worst toxicity grade and incidence according to dose levels during chemoradiation and up to 4 weeks afterwards (numbers of patients for each toxicity level shown)

\begin{tabular}{|c|c|c|c|c|c|c|c|c|c|c|c|c|c|c|c|c|}
\hline \multirow{2}{*}{ Toxicity grade $\mathrm{NCl}$ CTC } & \multicolumn{16}{|c|}{ Dose level } \\
\hline & \multicolumn{4}{|c|}{ I $n=3$} & \multicolumn{4}{|c|}{$2 n=6+8=14$} & \multicolumn{4}{|c|}{$3 n=7+16=23$} & \multicolumn{4}{|c|}{$4 n=6$} \\
\hline \multicolumn{17}{|l|}{ Haematologic } \\
\hline Anaemia & & 2 & & & 4 & 3 & & & & 5 & & & & 1 & & \\
\hline Leukopenia & & & & & I & 3 & I & & & & 3 & & & 2 & & \\
\hline Haemorrhage & । & & & & & & & & & I & & & & & & \\
\hline \multicolumn{17}{|l|}{ Infective } \\
\hline Non-neutropenic fever/infection (ANC $\geqslant 1.0 \times 10^{9-1}$ ) & I & & & & & 3 & & & & I & I & & 1 & & & \\
\hline Neutropenic fever/infection $\left(\mathrm{ANC}<1.0 \times 10^{9} \mathrm{I}^{-1}\right)$ & & & & & & । & & & & & । & & & & I & \\
\hline \multicolumn{17}{|l|}{ Biochemical } \\
\hline \multicolumn{17}{|l|}{ Gastrointestinal } \\
\hline Stomatitis & 2 & & & & 4 & & & & & । & & & & & & \\
\hline Nausea/vomiting & & 2 & & & 2 & 3 & & & & & 2 & & & I & & \\
\hline Diarrhoea & & 2 & & & 2 & 4 & 3 & & & & 6 & & & & I & \\
\hline Cholinergic syndrome & & & & & & & & & 3 & & & & & । & & \\
\hline \multicolumn{17}{|l|}{ Constitutional } \\
\hline Fatigue/lethargy & & 2 & & & 4 & 6 & & & & & 3 & & & 2 & & \\
\hline Anorexia & 2 & & & & 3 & 2 & & & & & 2 & & & I & & \\
\hline Weight loss & & & & & 2 & । & & & & 4 & & & & i & & \\
\hline \multicolumn{17}{|l|}{ Dermatology } \\
\hline Palmar plantar erythrodysesthesia (PPE) & I & & & & I & 2 & & & & & । & & । & & & \\
\hline Alopecia & & & & & & & & & 4 & & & & & 2 & & \\
\hline \multicolumn{17}{|l|}{ Cardiac } \\
\hline
\end{tabular}

Table 3 Number of patients at each dose level who experience the specified number of dose-limiting toxicities

\begin{tabular}{lcccc}
\hline & \multicolumn{4}{c}{ Dose level } \\
\cline { 2 - 5 } $\begin{array}{l}\text { Number of DLTs per } \\
\text { patient }\end{array}$ & $\mathbf{I}$ & $\mathbf{2}$ & $\mathbf{3}$ & $\mathbf{4}$ \\
\hline 1 & $\mathbf{n = 3}$ & $\mathbf{n = 6 + 8}=\mathbf{1 4}$ & $\mathbf{n}=\mathbf{7 + 1 6}=\mathbf{2 3}$ & $\mathbf{n = 6}$ \\
2 & - & 3 & 4 & 2 \\
3 & - & - & 3 & - \\
Total number of patients & - & - & 1 & - \\
experiencing at least one DLT & & $3 / 14$ & $8 / 23$ & $2 / 6$ \\
\hline
\end{tabular}

disease on their pre-CRT MRI scan were upstaged. Of 34 patients who had had N1 or N2 disease on their pre-CRT MRI scan, $30(88 \%)$ were judged to have had their $\mathrm{N}$ stage downstaged, four $(12 \%)$ unchanged and none upstaged.

\section{Surgery}

The median time between the last fraction of RT and surgery was 59 days (range 41-118 days). 41 patients underwent resection: three of three included at dose level 1, 13 of 14 at dose level 2, 20 of 23 at dose level 3 and five of six at dose level 4 . Thirty-one patients underwent an anterior resection, nine an abdominoperineal resection and one a Hartman's procedure. Twenty-two of the 31 patients having an anterior resection had a defunctioning stoma (17 ileostomy and five colostomy). Postoperatively the median inpatient stay was 11 days (range, 6-42 days).

The postoperative complications prospectively recorded as occurring within 30 days of surgery are shown in Table 6 . Of the 40 patients who underwent resection and were alive postoperatively none died within the 30 -day postoperative period. There were 7 pelvic or wound infections and two anastomotic and two perineal wound dehiscences.

\section{Histology}

Of 41 resected specimens, $11(27 \%)$ showed a pathological complete response (pCR; T0), two (5\%) were T1, four (10\%) T2, $23(56 \%)$ T3 and one $(2 \%)$ T4. Thirty-three $(80 \%)$ were N0, five $(12 \%) \mathrm{N} 1$ and three $(7 \%) \mathrm{N} 2$. The average nodal yield was 14 per specimen (range, 2-43). Numbers of patients showing a pCR/ number of resected specimens at each dose level were as follows: $1 / 3$ at dose level 1, 6/13 at dose level 2, 3/20 at dose level 3 and 1/5 
Consort flowchart of flow of patients through the NWCOG-2 phase I trial from recruitment to 30 days post operative

Forty seven patients consented to enter the trial

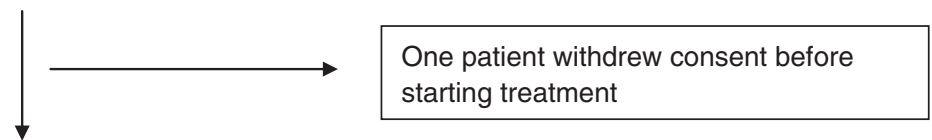

CRT: Dose level $1 n=3$, Dose level $2 n=14$, Dose level $3 n=23$, Dose level $4 n=6$

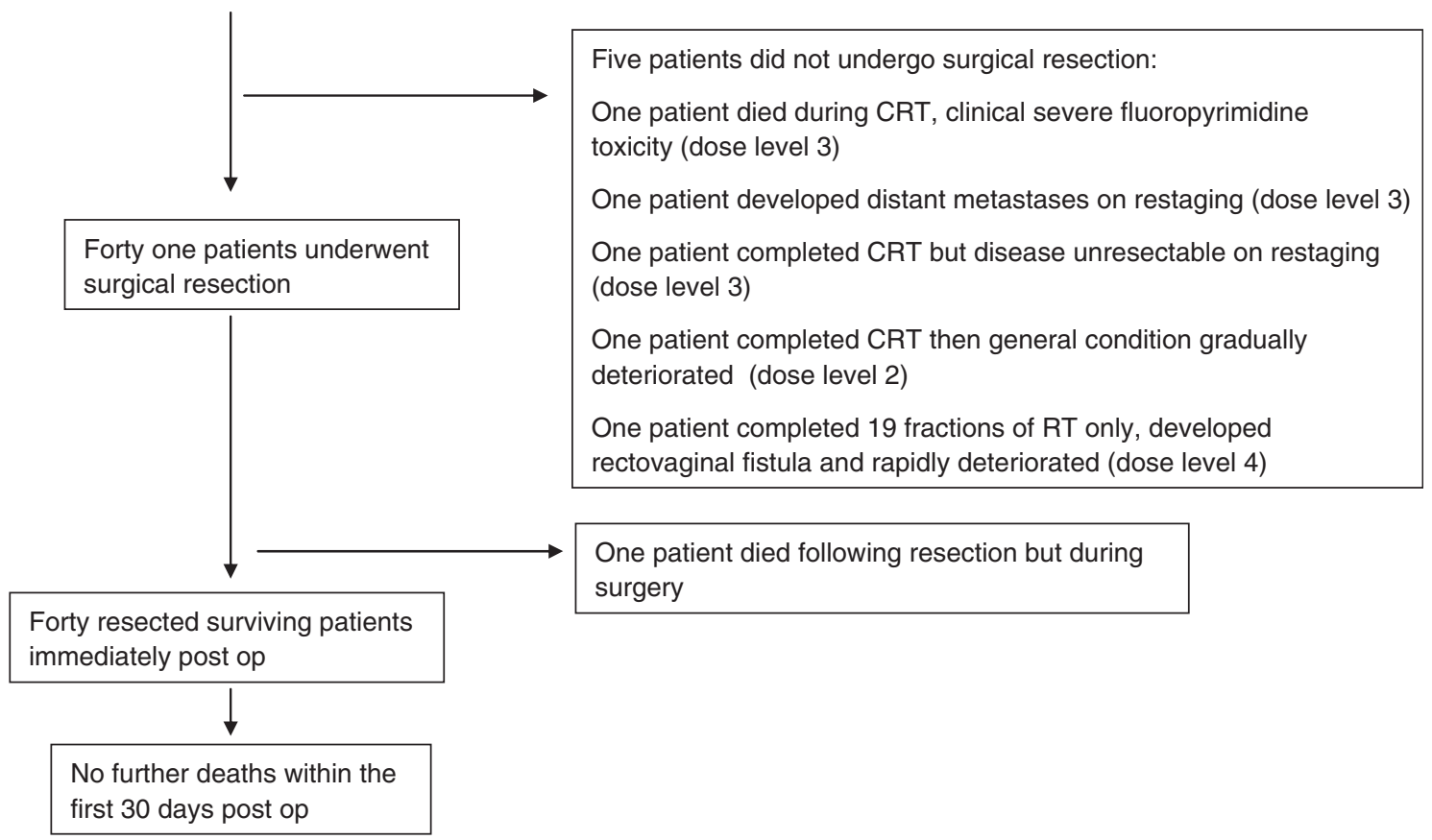

Figure I Consort flowchart of flow of patients through the NWCOG-2 phase I trial from recruitment to 30 days post operative.

Table 4 Dose intensity: Mean percentage of intended dose of radiotherapy, capecitabine and irinotecan that was delivered at each dose level

\begin{tabular}{lcccc}
\hline & $\begin{array}{c}\text { Dose } \\
\text { level I }\end{array}$ & $\begin{array}{c}\text { Dose } \\
\text { level 2 }\end{array}$ & $\begin{array}{c}\text { Dose } \\
\text { level 3 }\end{array}$ & $\begin{array}{c}\text { Dose } \\
\text { level 4 }\end{array}$ \\
\hline Patients per cohort & 3 & 14 & 23 & 6 \\
RT completed (\%) & 100 & 100 & 96 & 96 \\
lrinotecan completed (\%) & 100 & 96 & 94 & 93 \\
Capecitabine completed (\%) & 99 & 91 & 82 & 82 \\
\hline
\end{tabular}

at dose level 4 . Ten patients $(24 \%)$ had only microfoci of disease remaining $(2 \mathrm{~T} 1,3 \mathrm{~T} 2,5 \mathrm{~T} 3,9 \mathrm{~N} 0$ and $1 \mathrm{~N} 1)$.

Overall 36 of the 41 specimens $(88 \%)$ showed a histologically clear CRM (R0 resection) and five (12\%) an involved CRM (defined as $\leqslant 1 \mathrm{~mm}$ ). Three out of 26 patients whose RT was planned using fluoroscopy were CRM positive compared to 2 of 20 patients who underwent CT planning $\left(P=0.76\right.$ by $\left.\chi^{2}\right)$. Two of the five CRM-positive patients were in the low rectum, two mid and one upper and the post-CRT MRI predicted involvement in three of the five cases. Three CRM-positive cases were predominantly anterior and two predominantly posterior.

Comparing pre-CRT MRI scans with histology of the resected specimen (Table 7), 20 patients $(49 \%)$ had their T-stage downstaged and one (2\%) upstaged. Twenty-five of 32 initial MRI N1-2 patients $(78 \%)$ had their $\mathrm{N}$ stage downstaged and all of nine initial MRI N0 patients were N0 on resection.

\section{Long-term clinical outcome}

Although not formally the end point of this phase I trial, the median length of follow-up of patients was 41.2 months, which presented an opportunity to examine longer-term outcomes. For the whole group of 46 patients the 3 -year overall survival was $68.5 \%$ (Figure 2), disease-free survival $53.2 \%$ (Figure 3 ), pelvic disease-free survival $88.3 \%$ (Figure 4 ) and distant metastasis-free survival $67.0 \%$ (Figure 5). Of the 40 patients whose tumour was resected and were alive immediately postoperatively, two developed a local pelvic recurrence at 9 and 13 months post surgery. In all, 13 patients developed distant metastatic disease.

None of the five histologically CRM-positive cases developed locally recurrent disease on follow-up although two developed distant metastases, dying at 24 and 58 months. Of the other three CRM-positive patients, one died at 20 months of other causes and two were alive and well when last seen at 40 and 47 months.

\section{DISCUSSION}

This study is a phase I study examining the combination of irinotecan and capecitabine as concurrent radiation sensitisers in the downstaging CRT of locally advanced rectal cancer before attempting surgery. Among studies examining this CRT regimen 
Table 5 Pre-treatment MRI scan stage compared with post-chemoradiation MRI stage $n=43$

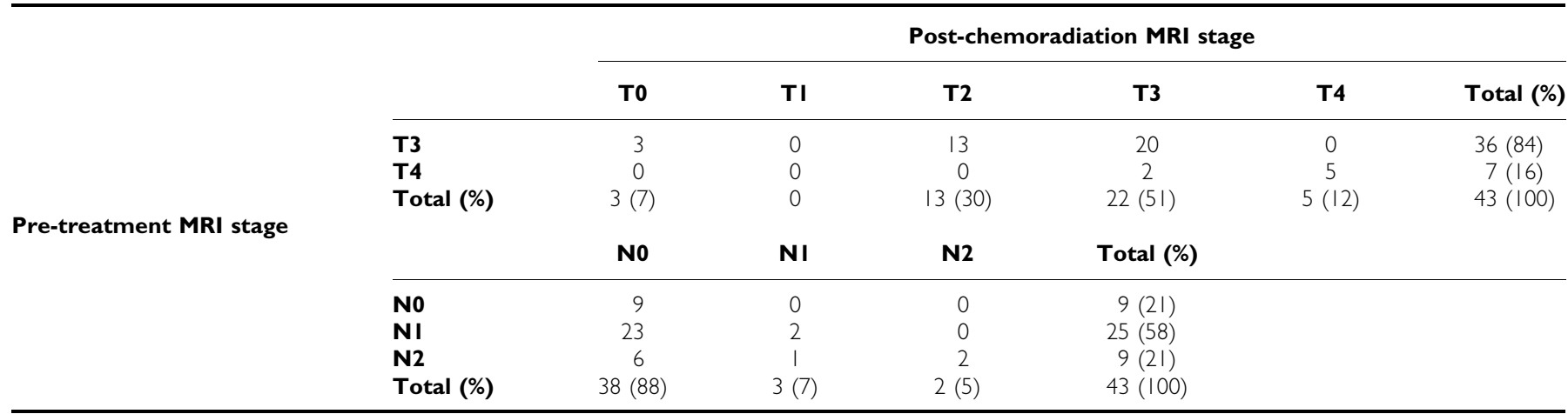

Table 6 Immediate post-operative complications (within 30 days of surgery) within the 40 patients undergoing resection and alive post operatively

\begin{tabular}{lc}
\hline Post-operative complication & Number of patients \\
\hline Pelvic infection & 4 (one with peritonitis also) \\
Wound infection & 3 \\
Serious infection elsewhere & 2 (chest, urinary) \\
Anastomotic dehiscence & 2 \\
Perineal wound dehiscence & 2 \\
Re-catheterisation necessary & 1 \\
Haemorrhage within the operative field & 0 \\
necessitating return to theatre & \\
Venous thromboembolic event & 0 \\
Myocardial infarction & 0 \\
Cerebrovascular accident & 0 \\
Ventilation needed for $>24 h$ postop & 0 \\
Acute respiratory distress syndrome & 0 \\
Death & 0 \\
Median time spent on ITU/HDU post op in & 0 (0- I4) \\
days (range) & \\
Readmission necessary after discharge & \\
Other serious post-operative complications & $4:$ (Atrial fribrillation) \\
& (Enteral feeding required) \\
& (Prolonged rectal drain) \\
& (Neurogenic bladder) \\
\hline
\end{tabular}

${ }^{a}$ One patient readmitted for femoral distal bypass following Hartmann's procedure, probably unrelated to rectal cancer treatment.

Table 7 Pre-treatment MRI scan stage compared to histology of the resected specimen $(n=4 I)$

\begin{tabular}{|c|c|c|c|c|c|c|c|}
\hline & & & Histolo & ogy of $r$ & resected s & specin & imen \\
\hline & & TO & TI & T2 & $\mathbf{T 3}$ & $\mathbf{T 4}$ & Total (\%) \\
\hline & $\begin{array}{l}\text { T3 } \\
\text { T4 } \\
\text { Total (\%) }\end{array}$ & $\begin{array}{c}9 \\
2 \\
11(27)\end{array}$ & $\begin{array}{c}1 \\
1 \\
2(5)\end{array}$ & $\begin{array}{c}4 \\
0 \\
4(10)\end{array}$ & $\begin{array}{c}20 \\
3 \\
23(56)\end{array}$ & $\begin{array}{l}1 \\
0 \\
1(2)\end{array}$ & $\begin{array}{c}35(85) \\
6(15) \\
41(100)\end{array}$ \\
\hline & & No & NI & N2 & Total (\%) & & \\
\hline & $\begin{array}{l}\text { N0 } \\
\text { N1 } \\
\text { N2 } \\
\text { Total (\%) }\end{array}$ & $\begin{array}{c}9 \\
20 \\
4 \\
33(80)\end{array}$ & $\begin{array}{c}0 \\
4 \\
1 \\
5(12)\end{array}$ & $\begin{array}{c}0 \\
0 \\
3 \\
3(7)\end{array}$ & $\begin{aligned} 9 & (22) \\
24 & (59) \\
8 & (20) \\
41 & (100)\end{aligned}$ & & \\
\hline
\end{tabular}

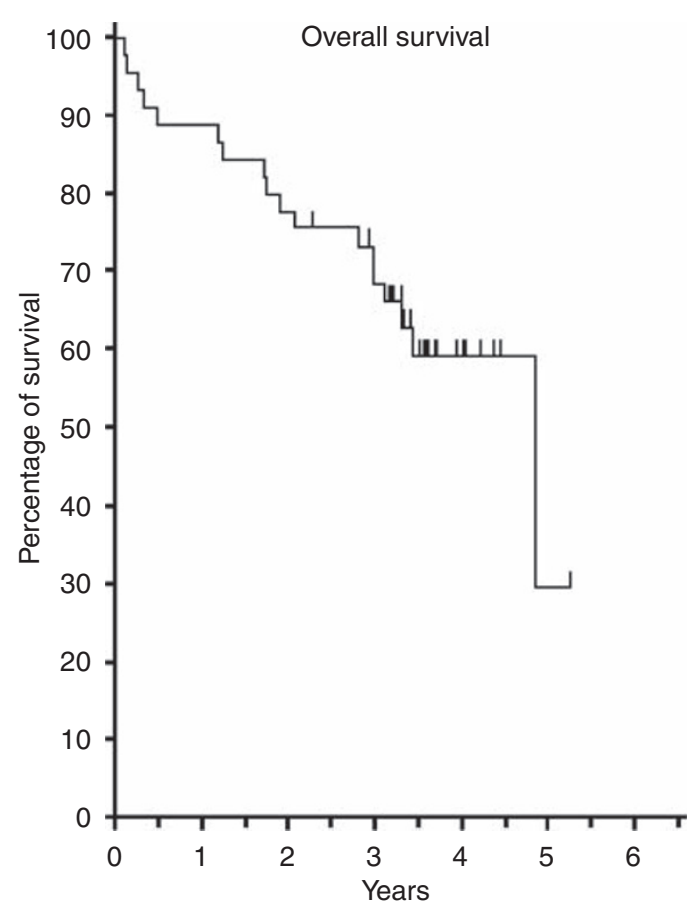

Figure 2 Overall survival $(n=46)$.

this study is unique in using MRI scanning as an inclusion criteria to show threatening or involvement of the mesorectal fascial excision plane by the primary tumour. MRI scanning is now regarded as the investigation of choice in staging rectal cancers with regard to this feature and judgment of operability or not, meaning that rectal cancers included in this study can be more confidently staged as 'locally advanced inoperable' than other studies hitherto published using this CRT regimen (Hofheinz et al, 2005; Klautke et al, 2006, 2007; Willeke et al, 2007) (Table 8). These have predominantly used trans-rectal ultrasound (TRUS) and CT scanning for staging, with no requirement for MRI staging. The poor-risk nature of the patients in our study was confirmed by the 53.2\% 3-year DFS (Figure 3).

In keeping with the above previously reported studies the predominant DLT encountered in this study was diarrhoea, with lesser degrees of fatigue, neutropenic sepsis, anorexia and PPE. No patient developed grade 4 diarrhoea and at our recommended dose level 2 of capecitabine $650 \mathrm{mg} \mathrm{m}^{-2}$ b.i.d. days $1-35$ and irinotecan $60 \mathrm{mg} \mathrm{m}^{-2}$ once per week during weeks $1,2,3$ and 4 combined 


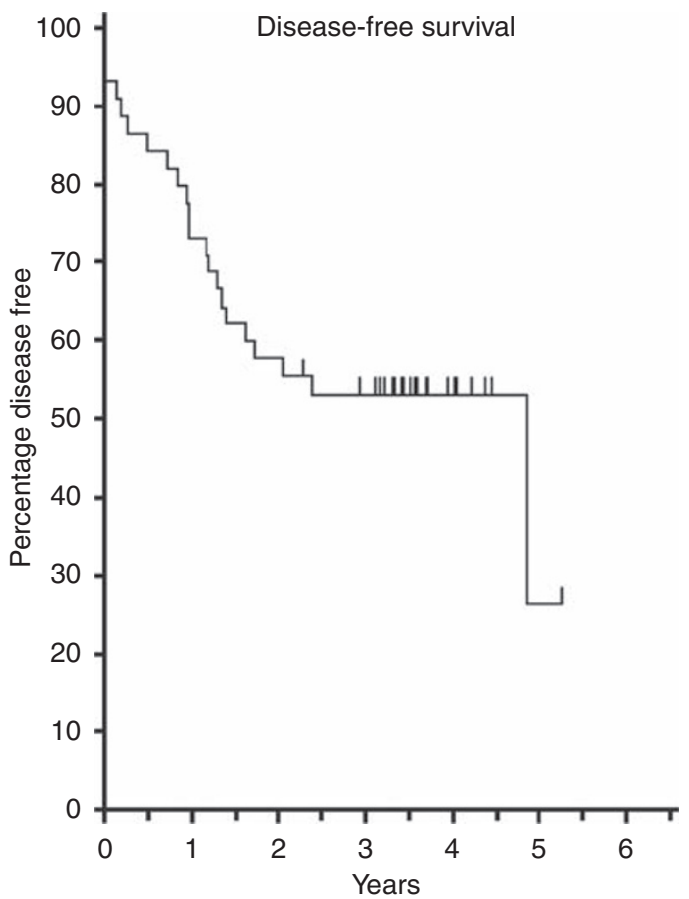

Figure 3 Disease-free survival $(n=46)$.

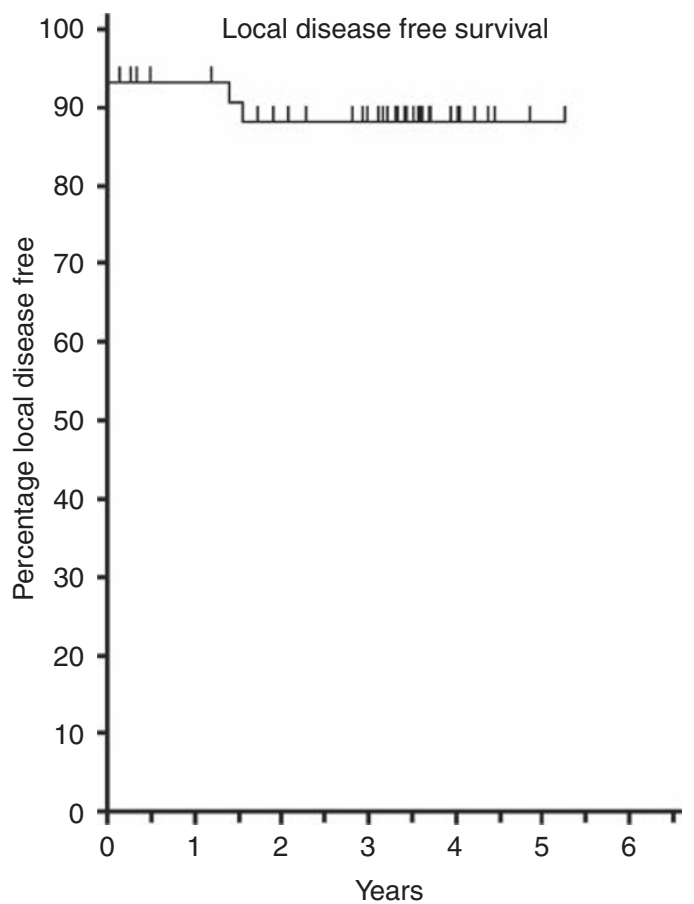

Figure 4 Local pelvic disease-free survival $(n=46)$.

with an RT dose of $45 \mathrm{~Gy}$ in 25 daily fractions over 5 weeks, we recorded acceptable acute toxicity with 3 of 14 patients $(21 \%)$ developing grade 3 diarrhoea.

In the study by Hofheinz et al (2005) the recommended dose was irinotecan at $50 \mathrm{mg} \mathrm{m}^{-2}$ once per week for five consecutive weeks $\left(250 \mathrm{mg} \mathrm{m}^{-2}\right.$ total) plus capecitabine at $500 \mathrm{mg} \mathrm{m}^{-2}$ b.i.d. 7 days per week on days 1-38 throughout a course of RT delivering $50.4 \mathrm{~Gy}$ in $1.8 \mathrm{~Gy}$ fractions over 5.5 weeks. Only one of 12 patients

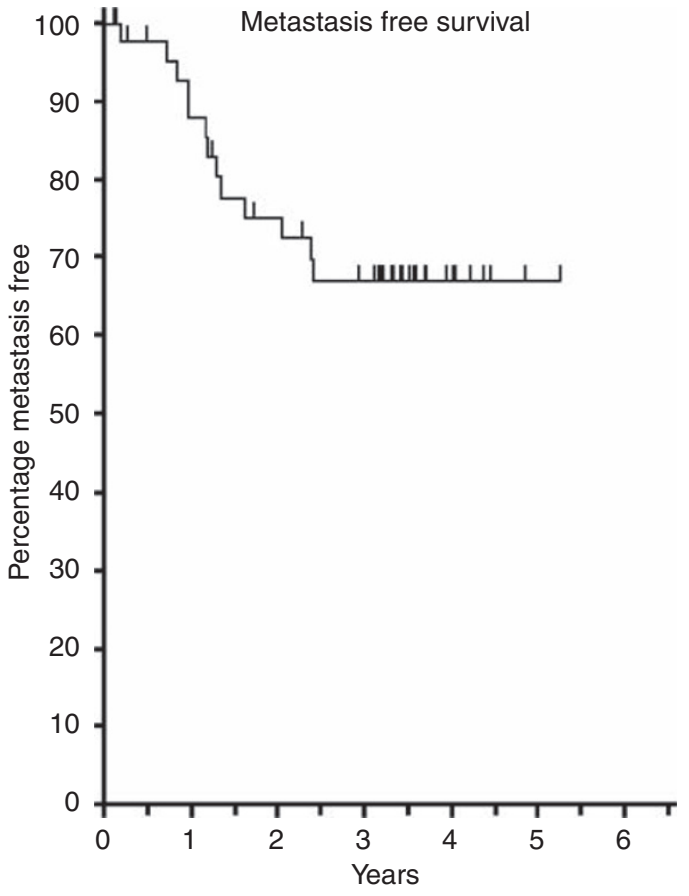

Figure 5 Distant metastasis-free survival $(n=46)$.

developed a serious toxicity (grade 3 fatigue). However, when the dose of capecitabine was increased to $625 \mathrm{mg} \mathrm{m}^{-2}$ b.i.d., three of seven patients developed grade 3 diarrhoea, one grade three nausea and one grade three anorexia.

Willeke et al (2007) treated 36 patients with a similar regimen to the recommended dose of Hofheinz et al (2005). Again, they found a relatively low rate of grade 3 diarrhoea $(11 \%)$ and fatigue $(3 \%)$ although $25 \%$ of patients had grade 3 or 4 leukopenia.

The recommended dose in the study by Klautke et al (2006) delivered an identical overall irinotecan dose to that in this study ( $240 \mathrm{mg} \mathrm{m}^{-2}$ total) although this was delivered in 6 rather than 4 weekly treatments. The recommended daily capecitabine dose at $750 \mathrm{mg} \mathrm{m}^{-2}$ b.i.d. was higher and delivered for a week longer (continuously days 1-43) than that in this study. The radiation dose was also $24 \%$ higher at $55.8 \mathrm{~Gy}$ delivered in 31 daily fractions over 6 weeks. At this dose level, however, 6 of 16 patients (38\%) developed grade 3 diarrhoea.

In view of the above, Klautke et al (2007) modified their regimen, maintaining the same daily dose of capecitabine at $750 \mathrm{mg} \mathrm{m}^{-2}$ b.i.d. but giving this for a total of 4 weeks only (weeks $1,2,4$ and 5) rather than for 6 weeks. In addition the total dose of irinotecan delivered was reduced to $200 \mathrm{mg} \mathrm{m}^{-2}$, given in the same 4 weeks in which capecitabine was delivered (weeks 1, 2, 4 and 5). In 20 patients this was well tolerated with $10 \%$ grade 3 diarrhoea but no histological specimen showed a pCR. This then prompted the use of an increased total irinotecan dose (to $240 \mathrm{mg} \mathrm{m}^{-2}$, in four treatment weeks 1, 2, 4 and 5) in a further 20 patients. The rate of grade 3 diarrhoea increased slightly (to 15\%) but seven specimens $(35 \%)$ now showed a pCR.

This study differs from the above initially in delivering a lower dose of $45 \mathrm{~Gy}$ of RT rather than $50.4-55.8 \mathrm{~Gy}$. In addition, smaller volumes of tissue were irradiated in this study compared with others with the maximum superior extent of the PTV at the sacral promontory. It is likely that the predominant acute toxicity seen of diarrhoea is largely caused by small bowel enteritis, partly because of the chemotherapy element but also partly because of small bowel in the radiation field. Klautke et al (2006) stipulated that the superior border of the radiation field included the fifth lumbar 
Table 8 Phase I/II studies of neoadjuvant rectal cancer CRT using concurrent capecitabine plus irinotecan

\begin{tabular}{|c|c|c|c|c|c|c|c|c|c|c|}
\hline Author & Phase & $\begin{array}{c}\text { Total } \\
\text { no. of } \\
\text { subjects }\end{array}$ & $\begin{array}{l}\text { Pelvic } \\
\text { staging } \\
\text { method }\end{array}$ & $\begin{array}{l}\text { Clinical } \\
\text { stage }\end{array}$ & RT dose & $\begin{array}{l}\text { Capecitabine } \\
\text { dose }\end{array}$ & $\begin{array}{l}\text { Irinotecan } \\
\text { dose }\end{array}$ & $\begin{array}{l}\text { Grade } 3 / 4 \\
\text { toxicity }\end{array}$ & $\begin{array}{l}\mathrm{PCR} \\
\text { rate }\end{array}$ & $\begin{array}{l}\mathrm{R} 0 \text { resection } \\
\text { rate }\end{array}$ \\
\hline \multirow[t]{2}{*}{$\begin{array}{l}\text { Hofheinz et al } \\
\text { (2005) }\end{array}$} & \multirow[t]{2}{*}{$\begin{array}{l}\text { I dose } \\
\text { escalation }\end{array}$} & \multirow[t]{2}{*}{19} & \multirow[t]{2}{*}{$\begin{array}{l}\text { TRUS } \\
\text { Pelvic CT }\end{array}$} & \multirow[t]{2}{*}{$\begin{array}{l}\text { T3 } n=18 \\
\text { T4 } n=1\end{array}$} & \multirow[t]{2}{*}{$\begin{array}{l}50.4 \mathrm{~Gy} \\
28 \mathrm{Fr} \\
5.5 \text { weeks }\end{array}$} & $\begin{array}{l}500 \mathrm{mg} \mathrm{m}^{-2} \\
\text { bd days I-38 }\end{array}$ & $\begin{array}{l}50 \mathrm{mg} / \mathrm{m}^{2} \\
\text { weekly } \times 5\end{array}$ & 1/12 gr 3 fatigue & \multirow[t]{2}{*}{$\begin{array}{l}4 \text { of } 19 \\
\text { resected } \\
=21 \%\end{array}$} & \multirow[t]{2}{*}{ NS } \\
\hline & & & & & & $\begin{array}{l}625 \mathrm{mg} \mathrm{m}^{-2} \\
\text { bd days I-38 }\end{array}$ & $\begin{array}{l}50 \mathrm{mg} / \mathrm{m}^{2} \\
\text { weekly } \times 5\end{array}$ & $\begin{array}{l}\text { 3/7 gr } 3 \text { diarrhoea } \\
\text { l/7 gr } 3 \mathrm{~N}+\mathrm{V} \\
\text { 1/7 gr } 3 \text { anorexia } \\
\text { 1/7 gr } 3 \text { leukopenia }\end{array}$ & & \\
\hline \multirow[t]{3}{*}{$\begin{array}{l}\text { Klautke et al } \\
(2006)\end{array}$} & \multirow[t]{3}{*}{$|/| \mid$} & \multirow[t]{3}{*}{28} & \multirow[t]{3}{*}{$\begin{array}{l}\text { TRUS } \\
\text { Pelvic CT }\end{array}$} & \multirow[t]{3}{*}{$\begin{array}{l}\text { T2 } n=2 \\
\text { T3 } n=18 \\
\text { T4 } n=8\end{array}$} & \multirow[t]{3}{*}{$\begin{array}{l}55.8 \mathrm{~Gy} \\
31 \mathrm{Fr} \\
6 \text { weeks }\end{array}$} & $\begin{array}{l}500 \mathrm{mg} \mathrm{m}^{-2} \\
\text { bd days I-43 }\end{array}$ & $\begin{array}{l}40 \mathrm{mg} / \mathrm{m}^{2} \\
\text { weekly } \times 6\end{array}$ & $0 / 3$ & \multirow[t]{3}{*}{$\begin{array}{l}4 \text { of } 25 \\
\text { resected } \\
=15 \%\end{array}$} & \multirow[t]{3}{*}{$24 / 25$ (96\%) } \\
\hline & & & & & & $\begin{array}{l}650 \mathrm{mg} \mathrm{m}^{-2} \\
\text { bd days I-43 }\end{array}$ & $\begin{array}{l}40 \mathrm{mg} / \mathrm{m}^{2} \\
\text { weekly } \times 6\end{array}$ & $0 / 3$ & & \\
\hline & & & & & & $\begin{array}{l}750 \mathrm{mg} \mathrm{m}^{-2} \\
\text { bd days I-43 } \\
825 \mathrm{mg} \mathrm{m}^{-2} \\
\text { bd days I }-43\end{array}$ & $\begin{array}{l}40 \mathrm{mg} / \mathrm{m}^{2} \\
\text { weekly } \times 6 \\
40 \mathrm{mg} / \mathrm{m}^{2} \\
\text { weekly } \times 6\end{array}$ & $\begin{array}{l}\text { 6/16 (38\%) gr } 3 \\
\text { diarrhoea } \\
3 / 6 \text { gr } 3 \text { diarrhoea } \\
\text { 2/6 gr } 4 \text { diarrhoea } \\
\text { 1/6 gr } 3 \text { HFS } \\
\text { 1/6 gr } 3 \text { leukopenia }\end{array}$ & & \\
\hline \multirow[t]{2}{*}{$\begin{array}{l}\text { Klautke et al } \\
(2007)\end{array}$} & $\|$ & 20 & $\begin{array}{l}\text { TRUS } \\
\text { Pelvic CT }\end{array}$ & $\begin{array}{l}\text { T3 } n=18 \\
\text { T4 } n=2\end{array}$ & \multirow[t]{2}{*}{$\begin{array}{l}55.8 \mathrm{~Gy} \\
31 \mathrm{Fr} \\
6 \text { weeks }\end{array}$} & $\begin{array}{l}750 \mathrm{mg} \mathrm{m}^{-2} \\
\text { bd days I-14, } \\
22-35\end{array}$ & $\begin{array}{l}50 \mathrm{mg} / \mathrm{m}^{2} \\
\text { weekly } \times 4 \\
\text { (days I, } 8 \\
22.29\end{array}$ & $\begin{array}{l}2 / 10(10 \%) \text { gr } 3 \\
\text { diarrhoea }\end{array}$ & 0 & $20 / 20100 \%$ \\
\hline & $\|$ & 20 & & $\begin{array}{l}\text { T2 } n=1 \\
\text { T3 } n=16 \\
\text { T4 } n=3\end{array}$ & & $\begin{array}{l}750 \mathrm{mg} \mathrm{m}^{-2} \\
\text { bd days I-I4, } \\
22-35\end{array}$ & $\begin{array}{l}60 \mathrm{mg} / \mathrm{m}^{2} \\
\text { weekly } \times 4 \\
\text { (days I, 8, } \\
22,29\end{array}$ & $\begin{array}{l}3 / 20(10 \%) \text { gr } 3 \\
\text { diarrhoea }\end{array}$ & $\begin{array}{l}7 \text { of } 20 \\
\text { resected } \\
=35 \%\end{array}$ & 19/20 (95\%) \\
\hline
\end{tabular}

Abbreviations: Day I = first day of RT; TRUS = trans rectal ultrasound; $N+V=$ nausea and vomiting; NS = not stated; HFS = hand foot syndrome. ${ }^{a}$ Recommended dose.

vertebral body and Hofheinz et al (2005) and Willeke et al (2007) stipulated that the upper border of the clinical target volume (CTV) was at $\mathrm{L} 4-5$ for $\mathrm{cN}$-positive patients and the lower border at $5 \mathrm{~cm}$ below macroscopic tumour. It is noteworthy that the superior field border had been reduced to the L5/S1 junction in the later report of Klautke et al (2007), possibly contributing to the reported reduction in acute toxicity.

We gave capecitabine continuously throughout RT including weekends to mimic the continuous infusion 5FU that was used in our previous study (Iles et al, 2008). At the recommended dose level 2 in this study the overall dose of capecitabine delivered was $45500 \mathrm{mg} \mathrm{m}^{-2}$ compared to $38000 \mathrm{mg} \mathrm{m}^{-2}$ in Hofheinz et al (2005) and Willeke et al (2007) and $64500 \mathrm{mg} \mathrm{m}^{-2}$ in Klautke et al (2006). We found that the component of our CRT regimen that was difficult to deliver in its entirety because of toxicity, as the dose levels were increased was the capecitabine. At dose level 3 at which a total dose of capecitabine of $57750 \mathrm{mg} \mathrm{m}^{-2}$ was intended to be given, a mean of only $82 \%$ of the intended dose could be delivered (Table 4). It is striking that Klautke et al (2007) needed to modify their capecitabine to achieve acceptable toxicity. Whether this was due to the two enforced weekly breaks or simply due to a reduction in the overall delivered dose to $42000 \mathrm{mg} \mathrm{m}^{-2}$ is unclear.

In contrast to the other studies mentioned above, we adopted a strategy of giving irinotecan weekly for the first 4 weeks of a 5week course of rectal CRT. This approach was similar to that used in our previous study when irinotecan was combined with continuous infusion 5FU throughout the course of RT (Iles et al, 2008). The rationale for this was to 'front-load' the irinotecan so that a dose would not be delivered in the final fifth week when diarrhoea was liable to be approaching its maximum. We found that at all dose levels a mean of at least $93 \%$ of the intended dose of irinotecan could be delivered.

Although not the primary end point of this study, the pCR rate of $27 \%$ in resected patients (or $24 \%$ by ITT) is promising and lies within the range of $15-35 \%$ reported by others (Table 8 ). The rate of histologically clear surgical CRM reported in this study ( $88 \%$ of resected specimens or $78 \%$ by ITT) is also encouraging, as is the low pelvic recurrence rate (Figure 4).

It is likely that the toxicity and tumour response resulting from the combination of a doublet of chemotherapy in addition to RT are complex and dynamic processes with potential marked resultant differences depending on the interplay of the chemotherapy administration schedule and dose and the RT volume, timing, dose and fractionation. The CRT regime (dose level 2) recommended for taking forward into further studies in the current report, would not be out of keeping with those recommended in the other studies although there are significant differences as outlined above. It may appear counter-intuitive to combine three agents (RT, capecitabine, irinotecan) all of which have the overlapping toxicity of diarrhoea although it does appear that at the doses recommended in this study the incidence of this toxicity at serious levels is acceptable. Indeed, at the doses recommended by ourselves and others, rates of diarrhoea reported are not dissimilar to those reported using the doublet of capecitabine plus oxaliplatin as radiation sensitisers in this context (Glynne-Jones et al, 2006).

The patient who died in this study on dose level 3 showed signs of severe fluoropyrimidine toxicity. It may be that this patient had a specific metabolic disorder such as dihydropyrimidine dehydrogenase deficiency increasing susceptibility to fluoropyrimidine 
toxicity although no specific testing for this was carried out. It does, however, emphasise the importance of giving patients on oral fluoropyrimidines clear advice that if they become unwell or show signs of fluoropyrimidine toxicity, especially if these are developing rapidly, then they must stop their tablets immediately and ring promptly for medical advice. For patients receiving aggressive treatment with a CRT regime such as that discussed in this report, this is especially important.

When considering downstaging CRT for rectal cancer, toxicity not only during CRT is important, but also expressed as postoperative morbidity. Hofheinz et al (2005) reported that of 19 resected patients, nine (47\%) experienced a variety of postoperative complications including wound dehiscence, bowel atonia, bladder dysfunction, recto-vaginal fistula, a presacral abscess needing drainage and anastomotic insufficiency and complicated secondary wound healing requiring revision. There were no intra- or postoperative deaths.

Willeke et al (2007), using a similar regimen to Hofheinz et al (2005), reported that of the 34 operated patients nine $(26 \%)$ had prolonged or complicated wound healing, eight $(24 \%)$ had temporary bowel atonia, three $(12 \%)$ developed an anastomotic leakage and three (12\%) an abscess. Two patients died postoperatively from septic complications.

Klautke et al (2006) reported that of 25 operated patients there was one anastomotic leakage and one bowel atonia treated conser- vatively. There were, however, two deaths, one from pneumonia and the other from sudden cardiac death. In their later report (Klautke et al, 2007) no detailed report of postoperative complications is presented other than to state that at the modified dose discussed above, there were no postoperative deaths.

In this study there was one death due to intraoperative bleeding and a consequent cardiac arrest in a patient on the operating table who had had their rectal cancer resected. No cause for this was found. In the 40 patients who underwent resection and were alive postoperatively there were no deaths within the first 30 days and postoperative morbidity (Table 6) did not appear to be unduly severe.

In conclusion, we have developed a CRT regime for use in the preoperative downstaging of locally advanced rectal cancer incorporating the chemotherapy doublet of capecitabine and irinotecan. This regime needs to be included in future studies in larger numbers of patients to determine whether any advantage is conferred compared with the use of a single agent fluoropyrimidine as a radiation sensitiser in this context.

\section{ACKNOWLEDGEMENTS}

This work was supported in part by a grant from Aventis Pharma and from Roche Products Ltd.

\section{REFERENCES}

Birbeck KF, Macklin CP, Tiffin NJ, Parsons WMPH, Dixon MF, Mapstone NP, Abbott CR, Scott N, Finan PJ, Johnston D, Quirke P (2002) Rates of circumferential resection margin involvement vary between surgeons and predict outcomes in rectal cancer surgery. Ann Surg 235: 449-457

Bosset J-F, Collette L, Calais G, Mineur L, Maingon P, Radosevic-Jelic L, Daban A, Bardet E, Beny A, Ollier J-C, for EORTC Radiotherapy Group Trial 22921 (2006) Chemotherapy with preoperative radiotherapy in rectal cancer. $N$ Engl J Med 355: 1114-1123

Chen AY, Ocunieff P, Pommier Y, Mitchell JB (1997) Mammalian DNA topoisomerase I mediates the enhancement of radiation cytotoxicity by camptothysin derivatives. Cancer Res 57: 1529-1536

Colorectal Cancer Collaborative Group (2001) Adjuvant radiotherapy for rectal cancer: a systematic overview of 8507 patients from 22 randomised trials. Lancet 358: 1291-1304

Gerard J-P, Conroy T, Bonnetain F, Bouche O, Chapet O, Closon-Dejardin M-T, Untereiner M, Leduc B, Francois E, Maurel J, Seitz J-F, Buecher B, Mackiewicz R, Ducreux M, Bedenne L (2006) Preoperative radiotherapy with or without concurrent fluorouracil and leucovorin in T3-4 rectal cancers: results of FFCD 9203. J Clin Oncol 24: 4620-4625

Glynne-Jones R, Dunst J, Sebag-Montefiore D (2006) The integration of oral capecitabine into chemoradiation regimens for locally advanced rectal cancer: how successful have we been? Ann Oncol 17: 361-371

Glynne-Jones R, Falk S, Maughan TS, Meadows HM, Sebag-Montefiore D (2007) A phase I/II study of irinotecan when added to 5-fluorouracil and leucovorin and pelvic radiation in locally advanced rectal cancer: a Colorectal Clinical Oncology Group study. Br J Cancer 96: 551-558

Hall NR, Finan PJ, al-Jaberi T, Tsang CS, Brown SR, Dixon MF, Quirke P (1998) Circumferential resection margin involvement after mesorectal excision of rectal cancer with curative intent. Predictor of survival but not local recurrence? Dis Colon Rectum 41: 979-983

Hofheinz RD, von Gerstenberg-Helldorf B, Wenz F, Gnad U, KrausTiefenbacher U, Muldner A, Hehlmann R, Post S, Hochhaus A, Willeke F (2005) Phase I trial of capecitabine and weekly irinotecan in combination with radiotherapy for neoadjuvant therapy of rectal cancer. J Clin Oncol 23: $1350-1357$

Iles SM, Gollins SW, Susnerwala S, Haylock B, Myint S, Biswas A, Swindell R, Levine E (2008) Irinotecan +5 -fluorouracil with concomitant pre-operative radiotherapy in locally advanced non-resectable rectal cancer: a phase I/II study. Br J Cancer 98: 1210-1216

Kapiteijn E, Marijnen CA, Nagtegaal ID, Putter H, Steup WH, Wiggers T, Rutten HJ, Pahlman L, Glimelius B, van Krieken JH, Leer JW, van de Velde CJ, Dutch Colorectal Cancer Group (2001) Preoperative radio- therapy combined with total mesorectal excision for resectable rectal cancer. $N$ Eng J Med 345: 638-646

Klautke G, Feyerherd P, Ludwig K, Prall F, Foitzik T, Fietkau R (2005) Intensified concurrent chemoradiotherapy with 5-fluorouracil and irinotecan as neoadjuvant treatment in patients with locally advanced rectal cancer. Br J Cancer 92: 1215-1220

Klautke G, Kuchenmeister U, Foitzik T, Ludwig K, Prall F, Klar E, Fietkau R (2006) Concurrent chemoradiation with capecitabine and weekly irinotecan as preoperative treatment for rectal cancer: results from a phase I/II study. Br J Cancer 94: 976-981

Klautke G, Kuchenmeister U, Foitzik T, Ludwig K, Semrau S, Prall F, Klar E, Fietkau R (2007) Intensified irinotecan-based neoadjuvant chemotherapy in rectal cancer: Four consecutive designed studies to minimize acute toxicity and to optimize efficacy measured by complete pathological response. Rad Oncol 85: 379-384

MacFarlane JK, Ryall RDH, Heald RJ (1993) Mesorectal excision for rectal cancer. Lancet 341: 457-460

Marijnen CAM, Nagtegaal ID, Kapiteijn E, Klein Kranenbarg E, Noordijk EM, van Krieken JHJM, van de Velde $\mathrm{CJH}$, and cooperative investigators of the Dutch Colorectal Cancer Group (2003) Radiotherapy does not compensate for positive resection margins in rectal cancer patients: report of a multicenter randomized trial. Int J Rad Oncol Biol Phys 55: $1311-1320$

Mawdsley S, Glynne-Jones R, Grainger J, Richman P, Makris A, Harrison M, Ashford R, Harrison RA, Osborne M, Livingstone JI, MacDonald P, Mitchell IC, Meyrick-Thomas J, Northover JMA, Windsor A, Novell R, Wallace M (2005) Can histopathologic assessment of circumferential resection margin after preoperative pelvic chemoradiotherapy for T3-T4 rectal cancer predict for 3-year disease-free survival? Int J Rad Oncol Biol Phys 63: $745-752$

Mehta VK, Cho C, Ford JM, Jambalos C, Poen J, Koong A, Lin A, Bastidas JA, Young H, Dunphy EP, Fisher G (2003) Phase II trial of preoperative 3D conformal radiotherapy, protracted venous infusion 5-fluorouracil, and weekly CPT-11, followed by surgery for ultrasound-staged T3 rectal cancer. Int J Radiat Oncol Biol Phys 55: $132-137$

MERCURY Study Group (2006) Diagnostic accuracy of preoperative magnetic resonance imaging in predicting curative resection of rectal cancer: prospective observational study. Br Med J 333: 779-782

Mohiuddin M, Winter K, Mitchell E, Hanna N, Yuen A, Nichols C, Shane R, Hayostek C, Willett C (2006) Randomized phase II study of neoadjuvant combined-modality chemoradiation for distal rectal cancer: Radiation Therapy Oncology Group Trial 0012. J Clin Oncol 24: 650-655 
Nagtegaal ID, Marijnen CA, Kranenbarg EK, van de Velde CJH, van Krieken JHJM (2002) Circumferential margin involvement is still an important predictor of local recurrence in rectal carcinoma: not one millimetre but two millimetres is the limit. Am J Surg Pathol 26: 350-357

Nagtegaal ID, Quirke P (2008) What is the role for the circumferential margin in the modern treatment of rectal cancer? J Clin Oncol 26: 303-312

Navarro M, Dotor E, Rivera F, Sanchez-Rovira P, Garcia JL, Vega-Villegas ME, Cervantes A, Garcia JL, Gallen M, Aranda E (2006) A phase II study of preoperative radiotherapy and concomitant weekly irinotecan in combination with protracted venous infusion 5-flourouracil, for resectable locally advanced rectal cancer. Int J Rad Oncol Biol Phys 66: 201 - 205

Quirke P, Dixon MF, Durdey P, Williams NS (1986) Local recurrence of rectal adenocarcinoma due to inadequate surgical resection. Histopathological study of lateral tumour spread and surgical excision. Lancet 328: 996 - 999

Quirke P, Steele R, Monson J, Grieve R, Khanna S, Couture J, O'Callaghan C, Myint AS, Bessell E, Thompson LC, Parmar M, Stephens RJ, Sebag-Montefiore D (2009) Effect of the plane of surgery achieved on local recurrence in patients with operable rectal cancer: a prospective study using data from the MRC CR07 and NCIC-CTG C016 randomised clinical trial. Lancet 373: $821-828$

Quirke P, Williams GT (1998) Minimum Dataset for Colorectal Cancer Histopathology Reports. Royal College of Pathologists: London

Sauer R, Becker H, Hohenberger W, Rodel C, Wittekind C, Fietkau R, Martus P, Tschmelitsch J, Hager E, Hess CF, Karstens J-H, Liersch T, Schmidberger H, Raab R, for the German Rectal Cancer Study Group (2004) Preoperative vs postoperative radiotherapy for rectal cancer. $N$ Engl J Med 351: $1731-1740$

Sawada N, Ishikawa T, Sekiguchi F, Tanaka Y, Ishitsuka H (1999) X-ray irradiation induces thymidine phosphorylase and enhances the efficacy of capecitabine (Xeloda) in human cancer xenografts. Clin Cancer Res 5: $2948-2953$

Wibe A, Moller B, Norstein J, Carlsen E, Wiig JN, Heald RJ, Langmark F, Myrvold HE, Soreide O (2002) A national strategic change in treatment policy for rectal cancer-implementation of total mesorectal excision as routine treatment in Norway. A national audit. Dis Colon Rectum 45: $857-866$

Willeke F, Horisberger K, Kraus-Tiefenbacher U, Wenz F, Leitner A, Hochhaus A, Robholz R, Willer A, Kähler G, Post S, Hofheinz R-D (2007) A phase II study of capecitabine and irinotecan in combination with concurrent pelvic radiotherapy (CapIri-RT) as neoadjuvant treatment of locally advanced rectal cancer. Br J Cancer 96: 912 -917 